$\S=-1$

\title{
Effect of Toxicity Concentration of Waste Lubricating Oil (Hazardous Noxious Substances) on Aquatic Life
}

\author{
Nor Munirah Bt Abdullah ${ }^{1}$, Nur Sabiha binti Mohd Aluwi ${ }^{1}$, Heekyung Park $^{2}$, Norashikin binti Ahmad Kamal ${ }^{1}$

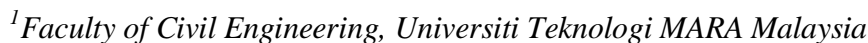 \\ ${ }^{2}$ Department of Civil and Environmental Engineering, Korea Advanced Institute of Science and Technology (KAIST) \\ *Corresponding author E-mail: normunirah88@gmail.com
}

\begin{abstract}
This lab scale study aims to investigate the effect of different concentration of waste lubricating oil on the African catfish juveniles, Clarias gariepinus. Five different concentrations of waste lubricating oil were used for 96 hours period which are $0 \mathrm{ml} / \mathrm{L}, 5 \mathrm{ml} / \mathrm{L}, 10 \mathrm{ml} / \mathrm{l}$, $15 \mathrm{ml} / \mathrm{l}$, and $20 \mathrm{ml} / \mathrm{L}$. After 96 hours of experiment, tank 4 which being added with $20 \mathrm{~mL}$ waste lubricating oil shows the highest percentage of fish mortality (100\%) followed by tank $3(95 \%)$, and tank $2(76 \%)$ while the lowest percentage of mortality is recorded in tank $1(19 \%)$. The result from the toxicity test showed that the higher the concentration of waste lubricating oil, the higher the mortality rate of fish. The lethal concentration LC50 that caused 50\% mortality of test fish was estimated at $8.1 \mathrm{ml} / \mathrm{L}$. From the observation, waste lubricating oil which contains heavy metals had cause damage to renal and nervous system of fishes thus causing them to lost equilibrium and irregular vertical swimming that will finally cause death. It can be concluded that the harmful environment that will trigger death of fish will be created by indiscriminate discharge of waste oil into water bodies. Therefore, it is recommended to treat the wastewaters, sewage and industrial wastes before it is being discharged into the aquatic ecosystems to sustain the aquatic species for the future. The proper effluent treatment technology should be adopted to check the present of oil spillage in the water. The enforcement of laws and legislations related to the protection of aquatic environment must be enhance and take into considerations.
\end{abstract}

Keywords: Waste lubricating oil, Clarias gariepinus, toxicity test, oil spillage, fish mortality

\section{Introduction}

Lubricants oil have been used basically to reduce friction between moving parts of different types of machinery or gear, enhance the efficiency of equipment, prevent corrosion and remove the heat to cool the engine. Production of engine oil and diesel is one of the importances of lubricants oil (Francois, 2006). Lubricants oil is become crucial to the modern society not only it is widely used to lubricate engine parts but also has been used broadly in industrial purposes, including agricultural and mining industries (Ssempebwa and Carpenter, 2009). Lubricating oils which come from the vehicles and engines are the largest sources for used oil in many developing countries, whereas small amount of lubricating oils are produced from hydraulic systems and minor industrial applications (Singh, Farooq, Raza, Mahmood, \& Jain, 2017). The amount of used oil from the vehicles and combustion engines rise rapidly due to the increase number of vehicles in the developing countries. Other than that, lubricating oil also effects the marine industry which contributed to the Hazardous Noxious Substances (HNS) especially if ship incident occurred (Neuparth et al., 2013).

According to Cunha, Moreira, \& Santos, (2015) there are 119 spills incidents occur from 1947 to 2011 and involved 187 spilled substance which are including spill incidents with non-toxic dissolvers, spill incidents with non-toxic sinkers, and spill incidents with persistent floater vegetable oil. The non-toxic dissolvers can give bad impacts to the environmental in term of acid and base. Usually, normal seawater value return to normality takes time a few hours or days. For example, there was a case of ammonium nitrate, which is a fertilizer and strong oxidizer has been reported to cause algal blooms and severe oxygen consumption that might asphyxiate aerobic living organisms. Next, non-toxic sinkers like cereals, seeds, bean, and some ores will cause a mechanical phenomenon of vegetation smothering and sediment covering. This phenomena will cause the emission of hydrogen sulfide, methanol and ethanol. Spill incident with vegetable oil can cause many damages to the environmental. Currently, vegetable oil is transported in large quantity to manufacture biodiesel and soap industries. Vegetable oil is a type of non-petroleum drifting oil where it can mix with other floating materials and form a floating crust or sink. This type of crust can be in term of solid pellets such as oily "chewing gum" balls that may be collected by hand. This situation can affect biodiversity seriously. For instance, fish death has been observed due to clogging of the digestive track.

Waste lubricating oil is usually refers as the used engine oil which is discharge from the engine parts of transportations including cars, buses, motorcycles, ships, boats as well as aircraft. The degradation of fresh lubricating components which is contaminated by metals, ash, carbon residue, varnish, and other materials is also known as waste lubricating oil. After a few thousand kilometers of driving, these oils need to be changed or removed from the vehicles so that the engines will be last as long as it could (Merai, 2015). The environment is at risk due to both industrialization and urbanization process, and the sustainable management of natural resources has become completely challenging. The increase number in traffic volume and active transportation of goods by water and land transports had cause the production of waste lubricating oil rise rapidly. Due to those activities, about 150 million Litres of waste lubricating oil is being produced annually in Malaysia (Fai- 
zul et al., 2012). The current Third Schedule of the Environmental Quality Act 1974, under the Environmental Quality (Sewage and Industrial Effluents) Regulations, 1979, regulations 8 (1), 8 (2) and 8 (3) has been revisited and the Department of Environment has proposed 8th Schedule for the Act which stipulate effluent discharge limits for parameters specific to domestic wastewater. The effluent discharge limits for oil and grease is $40 \mathrm{mg} / \mathrm{l}$. According to the Department of Environment Malaysia, the waste oil is categorized as scheduled waste under the First Schedule of the Environmental Quality (Schedule Wastes) Regulations 2005. Unfortunately, the problems related with waste lubricating oil remain unsolved due to the lack of enforcement of this law. Some studies have been done to solve the problem. For example, Faizul et al., (2012) used intelligent SoC Controller for engine oil sensing monitoring system. However, the benefit of the new invention is remaining unclear. Some studies about the toxicity of oil and oil spill chemical on aquatic organisms have been carried out. However, only a few of them dealt with acute toxicity of the waste lubricating oil on catfish species. Hence, this study was carried out to investigate the effect of different concentration of waste lubricating oil on catfish species, Clarias gariepinus.

\section{Methodology}

Juveniles of catfish, Clarias sp. with average length of $4.0 \pm 0.2$ $\mathrm{cm}$ were used in this experiment to determine its effect with a different concentration of waste lubricating oils. A total of 120 Clarias sp. juveniles were acclimatized at Environment Laboratory, Faculty of Civil Engineering, University Teknologi Mara (UiTM), Shah Alam for 10 days prior to the toxicity test experiment. The test fish were placed in big tank containing $30 \mathrm{~L}$ of de-chlorinated tap water. During the acclimatization stage, the fish juveniles were fed with pellet twice a day.

105 juveniles of Clarias sp. were exposed to five different concentrations of waste lubricating oil which were determined from range tests and these concentrations used were $0 \mathrm{ml} / \mathrm{L}, 5 \mathrm{ml} / \mathrm{L}$, $10 \mathrm{ml} / \mathrm{L}, 15 \mathrm{ml} / \mathrm{L}$ and $20 \mathrm{ml} / \mathrm{L}$. One control was included for each experiment. The experiment involved documenting the mortality of test fish and observing the behavioral changes of test fish toward the waste lubricating oil in 96 hours interval.

The behavioral changes and mortality of test fish were monitored every 3 hours, from 8 am to $5 \mathrm{pm}$ for the 96 hours period. Mortalities are recorded at $24 \mathrm{~h}, 48 \mathrm{~h}, 72 \mathrm{~h}$, and $96 \mathrm{~h}$ and the concentrations that kill $50 \%$ of the test fish (LC50) were determined. The dead fish was removed to avoid contamination of water.

Selected water quality parameters that are $\mathrm{pH}$, temperature and dissolved oxygen (DO) were determined for every 24 hour for all replication. Analysis on the heavy metals was carried out to determine the content of heavy metals in waste lubricating oil by using digestion method. Finally, the sample was analyzed in spectrophotometer to determine the present of heavy metal such as lead $(\mathrm{Pb})$, cadmium $(\mathrm{Cd})$, zinc $(\mathrm{Zn})$ and copper $(\mathrm{Cu})$.

Toxicological data involving mortality were analyzed by using probit analysis. The effect of different concentration of oil on each fish could be illustrated by the graph plot that represents the response of the fish to various concentration of waste oil. LC50 were determined based on the analysis that was done by using SPSS software.

\section{Result and Discussion}

Table 1: Summary of number of fish mortality in 96 hours interval

\begin{tabular}{|c|c|c|c|c|c|c|}
\hline Tank & $\begin{array}{c}\text { Concen- } \\
\text { tration } \\
\text { of waste } \\
\text { 1ubricat- } \\
\text { ing oil } \\
\text { (mL) }\end{array}$ & $\begin{array}{c}\text { Repli- } \\
\text { cate 1 }\end{array}$ & $\begin{array}{c}\text { Repli- } \\
\text { cate 2 }\end{array}$ & $\begin{array}{c}\text { Repli- } \\
\text { cate 3 }\end{array}$ & $\begin{array}{c}\text { Total } \\
\text { mor- } \\
\text { tality }\end{array}$ & $\begin{array}{c}\% \text { of } \\
\text { mortali- } \\
\text { ty }\end{array}$ \\
\hline 1 & 5 & 2 & 2 & 0 & 4 & 19 \\
\hline 2 & 10 & 4 & 6 & 6 & 16 & 76 \\
\hline 3 & 15 & 7 & 7 & 6 & 20 & 95 \\
\hline
\end{tabular}

\begin{tabular}{|c|c|c|c|c|c|c|}
\hline 4 & 20 & 7 & 7 & 7 & 21 & 100 \\
\hline Control & 0 & 0 & 0 & 0 & 0 & 0
\end{tabular}

Based on the Table 1, there are no mortality is recorded in the control tank. This is because no waste lubricating oil was added into the control tank. After 96 hours of experiment, tank 4 shows the highest percentage of fish mortality $(100 \%)$ followed by tank 3 $(95 \%)$, and tank $2(76 \%)$ while the lowest percentage of mortality is recorded in tank $1(19 \%)$. The percentage of mortality of test fish, Clarias sp. is strongly affected by the concentration of waste lubricating oil. The percentage of mortality has been increased as the concentration of waste lubricating oil increased which is from $19 \%$ to $100 \%$. Similar result was obtained in the study reported by Hasan et al., (2014), where the mortality of Oreochromis sp. is increased by $8 \%$ to $100 \%$ when the concentration of oil increased. In addition, Ayoola and Alajabo (2012) also reported the mortality of Black Jaw Tilapia is increased (from $2 \%$ to $98 \%$ ) with the increasing concentration of waste lubricating oil in 96 hours interval. In the study conducted by Hasan et al., (2014) on the effect of waste oil on tilapia, they reported that the concentration of oil that caused $100 \%$ mortality of test fish is $200 \mathrm{ml} / \mathrm{L}$. There are two different concentrations of waste lubricating oil needed to cause $100 \%$ mortality of test fish in these two studies. This result might be due to the different species used which is in this study Clarias sp. was used while in the other study Oreochromis sp. was used. Besides that, the other factor which may affect the different between two studies is the size of test fish. The size of test fish used in this study was $4.0 \pm 0.2 \mathrm{~cm}$ while $5.5 \pm 0.2 \mathrm{~cm}$ of test fish was used in the study conducted by Hasan et al., (2014). The juvenile and small size of fish is more sensitive to the changes in environment as compared to adult and bigger fish.

\section{Percentage of fish mortality after 96 hours}

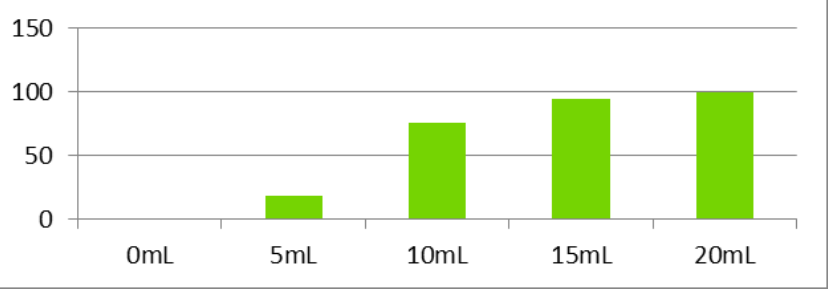

Fig. 1: Percentage of mortality of Clarias sp. after being exposed to waste lubricating oil

According to the Fig. 1, it can be concluded that more higher concentration of waste lubricating oil contributed to the more higher percentage of mortality of Clarias sp. juveniles. This might be due to the high concentration of heavy metal in the waste oil. Heavy metals are very toxic to fish as it can cause distraction to their growth thus causing them to die. Besides that, high concentration of waste oil (hazardous and noxious substance) can cause blockage of atmospheric oxygen from entering the water which thus may explain the high mortality among the fish.

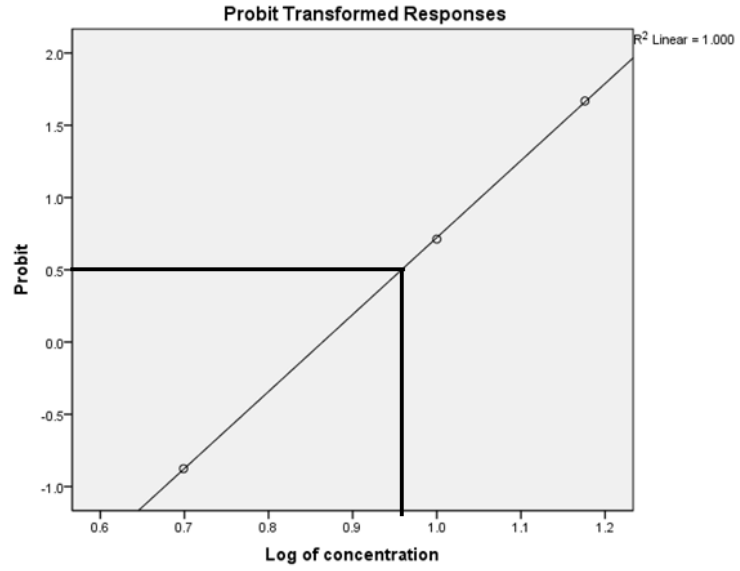

Fig 2: Regression graph of probit mortality $v s \log$ of concentration of waste lubricating oil 
Based on the regression graph as show in Fig 2., the concentration of waste lubricating oil that caused $50 \%$ mortality of test fish was $8.1 \mathrm{ml} / \mathrm{L}$. The smaller value of LC50 indicate that the toxicity level of the chemical. In this study, it can be concluded that the waste lubricating oil is very harmful to fish because only a small concentration of it can kill half of the total fish. In other study conducted by Ayoola et al., (2012), the LC50 value was $562 \mathrm{ml} / \mathrm{L}$. The different value of LC50 between these two studies is might be due to different size of test fish used where they used the bigger fish which is $8.0 \pm 0.2$ in length. The higher value of LC50 in their study is caused by the higher different concentrations of spent oil used which range from 60 to $900 \mathrm{ml} / \mathrm{L}$. One of the causes is the aquatic life affected by HNS. The 2000 OPRC-HNS Protocol (International Maritime Organization, 2000), designed for preparedness and response, defined Hazardous and Noxious Substance as a substance other than oil which likely to give harm to human health, harming the living resources and marine life, damage amenities or to interfere with other legitimate uses of the sea when it is introduced to the marine eco-systems. Three international codes were used to classify HNS involved in spills and collect information on the behavior, fate and weathering of the HNS once spilled in seawater which are the Standard European Behavious Classification (SEBC), International Maritime Dangerous Goods (IMDG) and Intermediate Bulk Container (IBC) codes. Based on the thorough literatures, HNS can be categorized into several numbers of groups. There are containment actions taken and lesson learned for the HNS groups respectively such as controlled release, monitoring plan, fish and selfish ban, water analysis and etc. The analysis of the incidents emphasizes the need to deepen our knowledge on several aspects related to preparedness and response to HNS spills which include i) HNS behavior at the sea and the development of HNS detection, forecasting, and risk analysis tools; ii) HNS hazards to humans and marine life; and iii) implementation of knowledge at the operational level to improve crisis management. The review was done based on 119 spill incidents that occured from 1947 to 2011 and is involving 187 spilled substances, where $96.7 \%$ of these incidents happen after 1970 . But it is safe to say that this review is an underestimated review as as many as 47 of the incidents have unknown amounts of spilled substances (undocumented). These HNS are generally is hazardous and detrimental to the health of organisms and environment itself. For the physical characteristic of the spills, according to IMDG code, $21 \%$ are flammable liquids, $16 \%$ are toxic substances, $13 \%$ are oxidizing substances, and $12 \%$ are corrosive substances. While according to IBC code, $7 \%$ are classified as major hazard, $61 \%$ as hazard, $22 \%$ as minor hazard. This numbers are big, $7 \%$ of 847,774 ton is a big number that is a major hazard to human lifes and to the ecosystem affected which is dangerous (Cunha et al., 2015). To solve this problem in the future an organized system to catalog substances carried aboard ships is needed to know which substances are spilled and quick actions must be carried out in order to tackle it before long term problems arise. For this to happen, it is also necessary to study more on the hazardous substances and its characteristics like physicochemical and toxicological properties of the substances that are involved.

Table 2: Mean water quality parameters of experiment

\begin{tabular}{|c|c|c|c|}
\hline $\begin{array}{c}\text { Effluent concentration } \\
(\mathrm{ml} / \mathrm{L})\end{array}$ & $\begin{array}{c}\text { Temperature } \\
\left({ }^{\circ} \mathrm{C}\right)\end{array}$ & $\mathrm{pH}$ & $\begin{array}{c}\text { Dissolved oxygen } \\
(\mathrm{mg} / \mathrm{L})\end{array}$ \\
\hline Control & 27.5 & 7.1 & 5.6 \\
\hline 5.0 & 26.2 & 6.8 & 4.8 \\
\hline 10.0 & 26.4 & 6.3 & 4.4 \\
\hline 15.0 & 25.8 & 5.6 & 3.7 \\
\hline 20.0 & 25.8 & 5.3 & 3.6 \\
\hline
\end{tabular}

The mean water temperature in all tanks ranged between $25.8^{\circ}$ to $27.5^{\circ} \mathrm{C}$. According to Elnady and Alkobaby (2010) the suitable and optimum temperature for the management of most fish culture is between $24^{\circ}$ to $30^{\circ} \mathrm{C}$. Hence, the temperature value from this study is considered suitable for Clarias sp. to survive. The mean of $\mathrm{pH}$ is ranged from 5.3 to 7.1 which is considered optimum range value for most fish species (Ajiboye et al., 2015). While for the dissolved oxygen, the mean value recorded in this study ranged from 3.6 to $5.6 \mathrm{mg} / \mathrm{L}$. Temperature is an important parameter when assessing water quality as it can affect other parameters including dissolved oxygen and $\mathrm{pH}$. Dissolved oxygen will be decreased when the temperature increases because warm water will not hold enough oxygen for the survival of aquatic organisms (Minnesota Pollution Control Agency, 2009). In addition, temperature also has correlation with $\mathrm{pH}$ of water. The rising in water temperature lead to declination of $\mathrm{pH}$ value. Lower $\mathrm{pH}$ value could lead to death of freshwater fish as they could not survive in the acidic condition (Robertson-Bryan Inc., 2014). The pH of water will be lowered when it is added with waste lubricating oil hence it could lead to the stressful environment to the fish thus cause them to die. Waste lubricating oil limit the oxygen supply to the fish juvenile because it can block the atmospheric oxygen from dissolved into water (Madanhire \& Mbohwa, 2016). The decrease in dissolved oxygen value is related to the increase of carbon dioxide concentration, thus explained the high mortality of test fish throughout the experiment(Madanhire \& Mbohwa, 2016). Water quality monitoring is very important in this study because it can provide information that will be useful to predict the suitable environment for the survival of most of freshwater fish. As can be seen from the result, the water quality especially dissolved oxygen is declined when the concentration of waste lubricating oil inclined. Thus, it can be concluded that water which is contaminated with waste oil is not suitable for the survival of Clarias sp.. Fish from the contaminated place are used in monitoring program as biomarker and can provide relevant biological and ecological information on the environmental pollution conditions. Hence, it can be a useful tool to establish guidelines for effective environmental management.

Table 3: Heavy metal content in waste lubricating oil

\begin{tabular}{|l|l|}
\hline Heavy metal content & Value $(\mathrm{mg} / \mathrm{kg})$ \\
\hline Lead & 1425 \\
\hline Cadmium & 910.5 \\
\hline Copper & 19.5 \\
\hline Zinc & 2.1 \\
\hline
\end{tabular}

Based on the table above, higher value of lead can be found in waste lubricating oil which is $1425 \mathrm{mg} / \mathrm{kg}$. Meanwhile the lowest content of heavy metal in waste oil is zinc which is $2.1 \mathrm{mg} / \mathrm{kg}$. Waste lubricating oil is a very harmful pollutant which contains polycyclic aromatic hydrocarbons (PAHs) and heavy metals. Heavy metals such as $\mathrm{Pb}, \mathrm{Zn}, \mathrm{Cu}$, and $\mathrm{Cd}$ which can be found in waste lubricating oil contain carcinogenic compound and are very toxic to organisms (Fu \& Wang, 2011). The individual growth rates, physiological function, mortality and fish reproduction will be affected by the toxic effects of these heavy metals (Afshan et al., 2014). In this study, the water $\mathrm{pH}$ is declined as the concentration of waste lubricating oil inclined. This may cause the heavy metals in the oil moved and released into water thus become toxic to the fish. As can be seen in the result, in lower concentration of waste lubricating oil $(5 \mathrm{ml})$, not all the test fish were killed and some of them showed abnormal swimming. In low concentration of heavy metals, the fish may not be killed but only caused chronic stress (Khayatzadeh and Abbasi, 2010). While in higher concentration of waste lubricating oil which is $20 \mathrm{ml}$, all test fish were died in within 24 hours of exposure. According to Zeitoun et al., (2014), higher concentration of heavy metals can cause damage to renal and nervous system of fishes thus causing them to lost equilibrium and irregular vertical swimming that will finally contribute to the death.

\section{Conclusion}

From the result obtained, it can be concluded that the higher concentration of waste lubricating oil contributed to the higher of the mortality rate of Clarias sp. juveniles. The median lethal concentration (LC50) value that killed $50 \%$ of test fish in this study is 8.1 $\mathrm{ml} / \mathrm{L}$. This indicates that only a smaller amount of waste oil is needed to cause mortality to half of total fish. The results represented the concentration of waste lubricating oil has strong posi- 
tive correlation with mortality of Clarias juvenile. However, the findings in this study is only limited to laboratory scale. There is need for further investigation in future to determine on the actual effect of waste lubricating oil in the aquatic environment and will beneficial to the related stakeholders on managing the emergency preparedness for hazardous noxious substance.

\section{Acknowledgement}

This research was supported by a grant [MPSS-CG-2015-01] through the Disaster and Safety Management Institute funded by Ministry of Public Safety and Security of Korean government and GIP Fund 600-IRMI/MyRA 5/3/GIP (006/2017), Universiti Teknologi Mara (UiTM).

\section{References}

[1] Afshan, S., Ali, S., Ameen, U. S., Farid, M., Bharwana, S. A., Hannan, F., \& Ahmad, R. (2014). Effect of Different Heavy Metal Pollution on Fish. Research Journal of Chemical and Environmental Sciences, 2(2), 35-40.

[2] Ajiboye, A. O., Awogbade, A. A., \& Babalola, O. A. (2015). Ef fects of water exchange on water quality parameters, nutrient utilization and growth of African catfish ( Clarias gariepinus ). International Journal of Livestock Production, 6(May), 57-60.

[3] Cunha, I., Moreira, S., \& Santos, M. M. (2015). Review on hazardous and noxious substances (HNS) involved in marine spill incidents-An online database. Journal of Hazardous Materials, 285(August), 509-516.

[4] Elnady, M., \& Alkobaby, A. (2010). Effect of fertilization and low quality feed on water quality dynamics and growth performance of Nile tilapia (Oreochromis niloticus). Journal of ..., 6(10), 10441054

[5] Fu, F., \& Wang, Q. (2011). Removal of heavy metal ions from wastewaters: A review. Journal of Environmental Management, 92(3), 407-418.

[6] International Maritime Organization. (2000). 2000 Protocol on Pre paredness, Response and Cooperation to Pollution Incidents by Hazardous and Noxious Substances. Retrieved September 29, 2017, from

http://www.imo.org/en/About/Conventions/ListOfConventions/Pag es/Protocol-on-Preparedness,-Response-and-Co-operation-topollution-Incidents-by-Hazardous-and-Noxious-Substances(OPRC-HNS-Pr.aspx

[7] Khayatzadeh, J., \& Abbasi, E. (2010). The effects of heavy metals on aquatic animals. The 1st International Applied Geological Congress, Department of Geology, Islamic Azad University-Mashad Branch, Iran, 1(April), 26-28.

[8] Madanhire, I., \& Mbohwa, C. (2016). Mitigating environmental impact of petroleum lubricants. Mitigating Environmental Impact of Petroleum Lubricants, (Freedonia 2013), 1-239.

[9] Minnesota Pollution Control Agency. (2009). Low Dissolved Oxygen in Water- Causes, Impact on Aquatic Life - An Overview. Minnesota Pollution Control Agency, 11(2), 2.

[10] Neuparth, T., Capela, R., Rey-Salgueiro, L., Moreira, S. M., Santos, M. M., \& Reis-Henriques, M. A. (2013). Simulation of a hazardous and noxious substances (HNS) spill in the marine environment: Lethal and sublethal effects of acrylonitrile to the european seabass. Chemosphere, 93(6), 978-985.

[11] P., M. Y. (2015). Rerefining of Used Lubricating Oils. International Journal of Scientific \& Engineering Research, 6(3), 329-332.

[12] Robertson-Bryan Inc. (2014). pH Requirements of Freshwater Aquatic Life, (May), 1-13.

[13] Singh, Y., Farooq, A., Raza, A., Mahmood, M. A., \& Jain, S. (2017). Sustainability of a non-edible vegetable oil based biolubricant for automotive applications: A review. Process Safety and Environmental Protection, 111, 701-713.

[14] Ssempebwa, J. C., \& Carpenter, D. O. (2009). The generation, use and disposal of waste crankcase oil in developing countries: A case for Kampala district, Uganda. Journal of Hazardous Materials, $161(2-3), 835-841$.

[15] Sunmonu, T. O., \& Oloyede, O. B. (2007). Biochemical assessment of the effects of crude oil contaminated catfish ( Clarias gariepinus ) on the hepatocytes and performance of rat. African Journal of Biochemistry Research, 1(5), 83-89.
[16] Ugwu, L.L.C., Ude E.F., Nwamba, H.O. and Chima, I. N. (2011). Effect of Crude Oil and Some Petroleum Products on Clarias Gariepinus. Continental J. Fisheries and Aquatic Science, 5(1), 24 30

[17] Zeitoun, M. M., Sayed, E.-, \& Mehana, E. (2014). Impact of Water Pollution with Heavy Metals on Fish Health: Overview and Updates. Global Veterinaria, 12(2), 219-231. 